\title{
The effect of COVID-19 on customer traffic: A case study of Food and Beverage stores in Erie County, New York
}

\author{
Joseph Aversa \\ Ted Rogers School \\ of Management, \\ Ryerson University \\ javersa@ryerson.ca
}

\author{
Xuan Quach \\ Ted Rogers School \\ of Management, \\ Ryerson University \\ xuan.quach@ryerson.ca
}

\author{
Tony Hernandez \\ Ted Rogers School \\ of Management, \\ Ryerson University \\ thernand@ryerson.ca
}

\author{
Ravi Vatrapu \\ Ted Rogers School \\ of Management, \\ Ryerson University \\ vatrapu@ryerson.ca
}

\begin{abstract}
The declaration of the COVID-19 pandemic and the resulting lockdowns brought focus on the importance of the retail sector for community well-being. The restrictive government policies that were put into place to curb the spread of COVID-19 virus added pressure on retailers to adapt to the subsequent changes in consumption. This research, using a case study of Erie County in the State of New York (NY), investigates these changes in visitation patterns for a commercial service sector that was deemed 'essential' - food and beverage. This study uses mobile location data to identify variations in shopping patterns for independent and chain stores. The study finds that by comparing the pre-pandemic to pandemic, there were changes to visitation patterns over time and between retail types. While the study highlights the potential to use mobile data to study shifts in consumption behaviours, the paper also reveals several challenges in using such data.
\end{abstract}

\section{Introduction}

On March 11, 2020, the World Health Organization declared COVID-19 a pandemic, setting in process global economic, social and political uncertainty [1]. During the pandemic, the retail industry has come to the forefront of public attention [2]. The public's perceptions around the retail industry have largely transformed from profit focused to now being characterized as essential to community well-being $[3,4,5]$. This new perspective has gained significant research interest, with special attention given to both the necessity and complexities around access to and availability of goods and services $[6,7]$.

Changes in demand, product hoarding, route suspensions, reductions to shipping capacity, and price gouging have grown to be significant nodes of dialogue and often points of contention [2]. This has created added pressures on retailers attempting to find ways to survive during this unprecedented situation [8].

Finding ways to maintain societal and economic relevance while navigating government interventions (e.g., partial or complete lockdowns restricting movement, social distancing protocols, and curfews) has been a priority for many retailers. While many of these restrictive policies have created severe challenges for the retail industry, some retail sectors have been disproportionately affected. It has been widely documented that non-essential retailers and small businesses have experienced some of the greatest challenges $[9,10]$. Changes to purchasing habits, increased vacancy rates, and unemployment rates will continue to present current and future disruptions to the retail industry [11].

To examine these changes in consumer behaviour, this study utilizes mobile location data for Erie County, NY to investigate the changes in shopping behaviours during the pandemic. This research has two objectives: (i) To identify the changes in consumer behaviours (visitor counts and dwell times) pre and during the pandemic; and (ii) to examine the different experiences in consumer shopping between independent and chain retailers.

The paper is divided into four sections, as follows: (i) the research context is provided, highlighting the public policy response to COVID-19 and the effect of such government intervention on consumer behaviour; (ii) the methodology is outlined; (iii) the research findings are presented and discussed; and, (iv) conclusions are drawn and limitations are identified.

\section{Research Context}

\subsection{COVID-19 Timeline in Erie County}


Accumulated evidence has shown a clear relationship between government policies and the number of COVID19 cases and fatalities [12]. From March 2020 to April 2021, Erie County went through five phases of government enforced restrictions and re-openings (Figure 1). On March 22, 2020, New York State implemented a 'PAUSE Executive Order' due to the significant rise of COVID-19 cases in the State. This executive order was a 10-point policy designed to ensure public safety [13]. As it pertains to retail, this policy outlined closures of all non-essential businesses and ordered all non-essential gatherings of individuals to be postponed or cancelled. On May 5th, 2020, New York State released regional guidelines for re-opening known as the NY Forward Plan, outlining four phases for reopening the state. By June $1^{\text {st }}$, retail businesses in New York State were eligible to reopen at reduced capacity (50\%), excluding malls which eventually were able to re-open on September $9^{\text {th }}$ [13]. On October 4th, amidst another surge in COVID-19 cases, non-essential businesses were once again forced to close in areas deemed to be hotspots for infection. In November, curfews for specific business services were put into effect restricting hours of operation, specifically restaurants and gyms [13]. January through to April, 2021 was largely defined by vaccination rollout and the gradual reopening of the economy.

\subsection{Mobile location data}

The advancements in spatial big data and associated analytics have allowed for more granular level consumer behaviour data to be collected and analyzed. The retail, tourism, management, and health care industries have started to experience significant changes in their informatics and decision-making as a result of this data evolution $[14,15,16,17,18,19,20,21,22,23]$. Spatial big data are becoming a more prominent research area $[24,25,26,27]$. Specifically, the adoption of Geographic Positioning System (GPS) technology within mobile devices (i.e., smartphones) has resulted in significant growth in the collection and analysis of spatial-temporal data. With GPS devices becoming cheaper and more portable, it is becoming easier to track individual travel patterns. With personal mobility being important in retail analytics, GPS data has led to the increased sophistication and quality of individual mobility data and as a result has experienced growth in its usage in understanding the successes and failures of retail locations [28, 29]. Traditionally, consumer retail metrics (e.g., conversion rate, customer retention, customer satisfaction, and store media value) were evaluated via qualitative surveys, often lacking the capability of capturing the nuances in consumer buying behaviour [30,31,32,33]. The use of

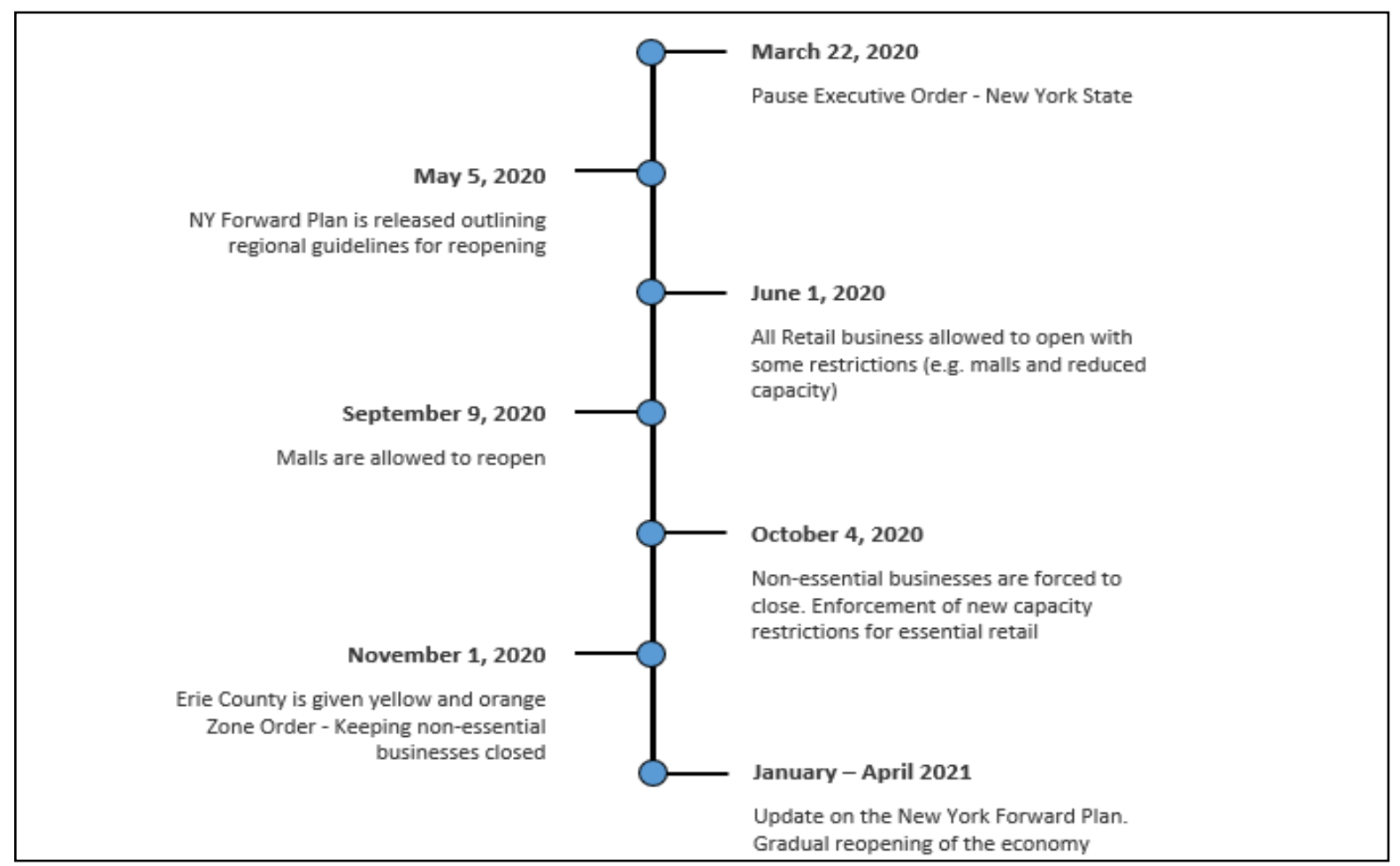

Figure 1. Summary of COVID stages in Erie County 
mobile data now allows for the minutia of individual consumer behaviors to be investigated at a micro level.

\subsection{Changes in consumer behaviours}

Under the threats of COVID-19, consumers have changed (or been forced to change) their shopping habits to protect themselves from getting infected. Short-term changes including cooking at home more often, fewer grocery trips, and prioritizing convenience when choosing stores are becoming standard practices [34]. When shopping, consumers are prioritizing safer in-store environments, often seeking shopping destinations with mobile-based self-checkout systems [35]. Consumers are becoming more cautions when considering shopping destinations as in-store cleanliness and health \& safety have also grown in importance for consumers [36]. To decrease the risk of getting infected, it has been documented that consumer are shopping less often at bricks and mortar locations, minimizing the amount of time spent in stores, avoiding standing in crowded places, and wearing gloves and masks while shopping [37].

In response to these changes in consumer behaviors, retailers have adopted new ways to enhance customer experience both in-store and online (i.e., adjusting daily store operations). Retailers are further prioritizing the introduction of new health and safety protocols to ensure consumer and employee safety. It has become common practice for retailers to offer free hand sanitizer, providing protective visors or face shields for cashiers, implementing social distancing measures between customers through floor signaling and graphic reminders, accepting only contactless payment to minimize the handling of cash, and requiring shoppers to wear gloves and/or face masks. Furthermore, due to the increasing demand in online shopping, many retailers have invested heavily in upgrading their online services to meet this need [38]. Researchers have started to investigate the effectiveness of these new shopping protocols. For example, Untaru and Han (2021) showed that there was a positive correlation between in-store protective measures and customer satisfaction [36]. Stores that strictly implement safety measures leave a positive effect on customer behavioural intentions, such as revisiting the store and positive word-of-mouth.

Not all businesses are able to adapt to the changes in consumer behaviour, which ultimately make it difficult for some retailers to attract customers. This study looks at the differences in aggregated weekly customer behaviour data between independents and chained stores to provide empirical evidence into the fluctuations in demand for instore shopping during the pandemic. By highlighting the potential differences between retail chains and independent stores, key vulnerabilities can be identified. This offers a potential critique on the restrictive government policies and how they might produce different outcomes for different types of businesses. This is an area of limited research and as a result this study allows for a preliminary look into fluctuations in customer traffic and the potential effects that it might have on the demand for retail spaces.

\section{Methodology}

\subsection{Study Area and Data}

Erie County is located along the shores of Lake Erie in western New York State (Figure 2). Erie County is home to approximately 916,672 people making it the $9^{\text {th }}$ largest county in the State [33]. The Buffalo metropolitan area accounts for $86 \%$ of the total population for the county [39].

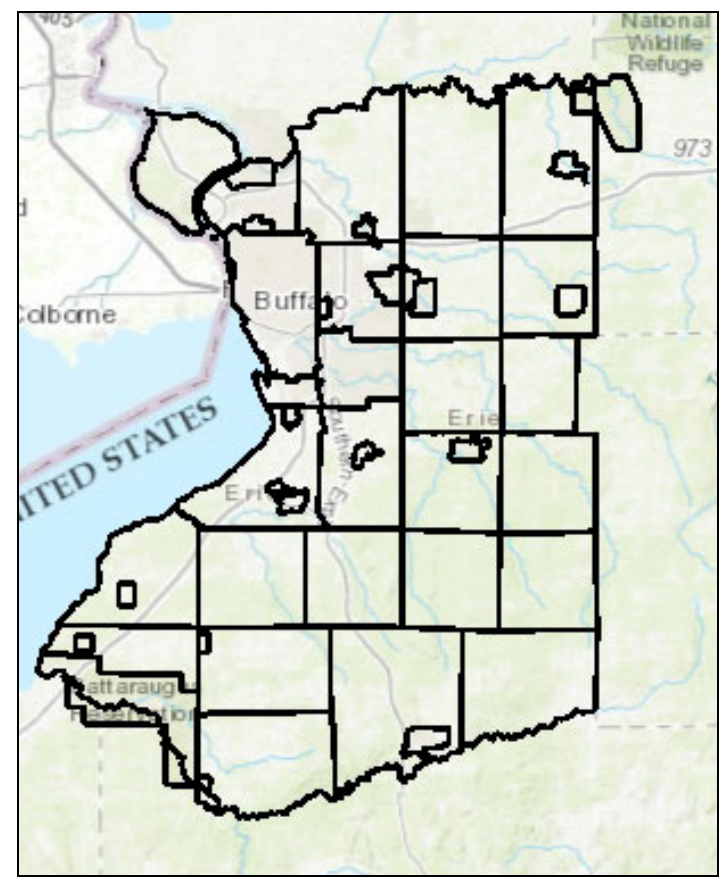

Figure 2: Erie County

The data included in this study was collected from SafeGraph which is a commercial provider of visitation pattern data derived from mobile devices. While SafeGraph does not offer pathing or trajectory data, it does provide aggregated visitation data for specific Points of Interest (POI). Weekly POI visitation numbers were collected for 602 food and beverage locations, in Erie County, NY from March 18, 2019 to February 22, 2021. These 602 locations make up the entire food and beverage (NAICS category 445) POI database available through SafeGraph in this study area. 


\subsection{Analysis}

Multiple approaches were used to analyze the spatial temporal visitation patterns at different time scales. This research consisted of the following three tasks: (i) comparing weekly aggregated visitation patterns for the food and beverage retail sector; (ii) comparing weekly visitation patterns across different business types (i.e., chain vs independent); and (iii) identifying the effects of the pandemic on retail visitation patterns for both chains and independent retailers.

The analysis of unique visitor data between chains and independent food and beverage stores were compared before and during the pandemic. The POI data were placed into two groups, chain and independent. This data was further investigated to identify if differences existed around consumer shopping behaviours during the study period. This was done using a paired two sample t-test. With essential businesses being allowed to remain open, the t-test was used to identify whether differences existed in consumer visitation patterns pre and during the pandemic.

\section{Findings}

When comparing visitor counts pre and during the pandemic, there are some notable changes in visitor data (Figure 3). In March, June and August the visitor counts were higher during the pandemic than that of the previous year. The increase in March (29\%) can be attributed to the increased demand in essential goods, panic buying and product hoarding. These were commonly documented experiences $[40,41]$ leading up to government sanctioned lockdowns that were put into place at the end of March.

At the time of reopening (June 2020), once again, pandemic visitor numbers exceeded the counts from the previous year (14\% increase). Shopping outings became more common in June when many of the stores' capacity restrictions were lessened or completely removed. During the fall months, COVID-19 counts began to rise and as a result, new restrictions were put into place, once again effecting the number of visitors within stores. The decline during the holiday shopping season was significantly less than what was experienced in pre-pandemic times $(49 \%$ decline). This was largely explained by new lockdowns being enforced in November and December as a result of surging infection rates.

When investigating the differences between visitor counts from March 2019 - February 2021 there are fluctuations in the total number of visitors (Figure 4). With the WHO declaring the pandemic in March of 2020, this triggered a significant decline in the total count of visitors. Chain stores experienced a $53.3 \%$ decline in traffic between March and April 2020 and 53.3\% between April 2019 and April 2020. For Independent stores, the decline was less extreme as visitor counts fell only $43 \%$ between March and April 2020. When comparing April 2019 to April 2020 independent stores experience a $52.5 \%$ decline in visitors. Through May and June, the total visitor count started to increase back to March totals. While counts for chain and independent retailers were relatively stable in the summer months (June-August), the second wave of the pandemic brought further declines in visitor counts (November -January).

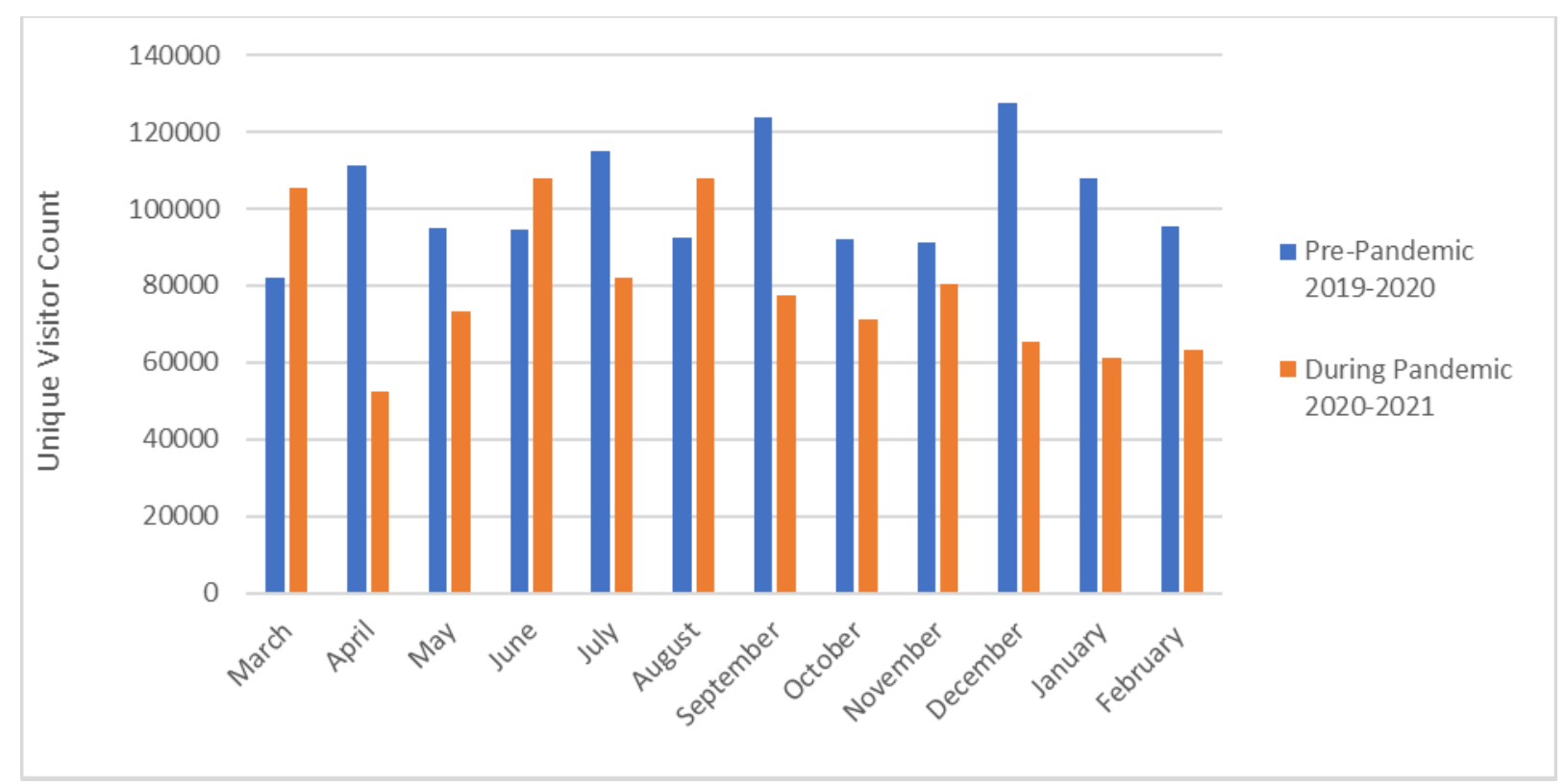

Figure 3. Visitor data for food and beverage stores 


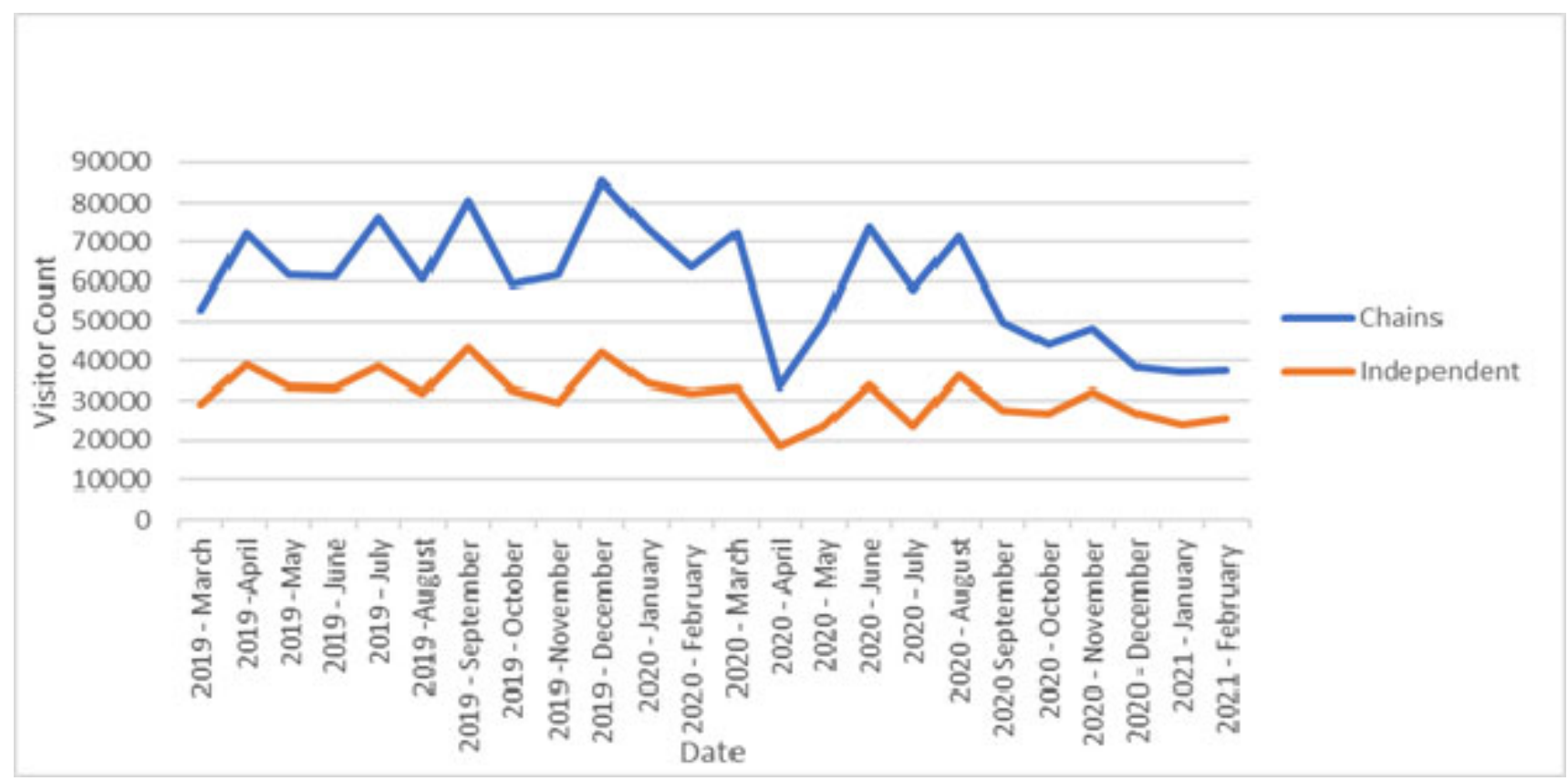

Figure 4. Chain and independent food and beverage stores visitor counts from March 2019 - February2021

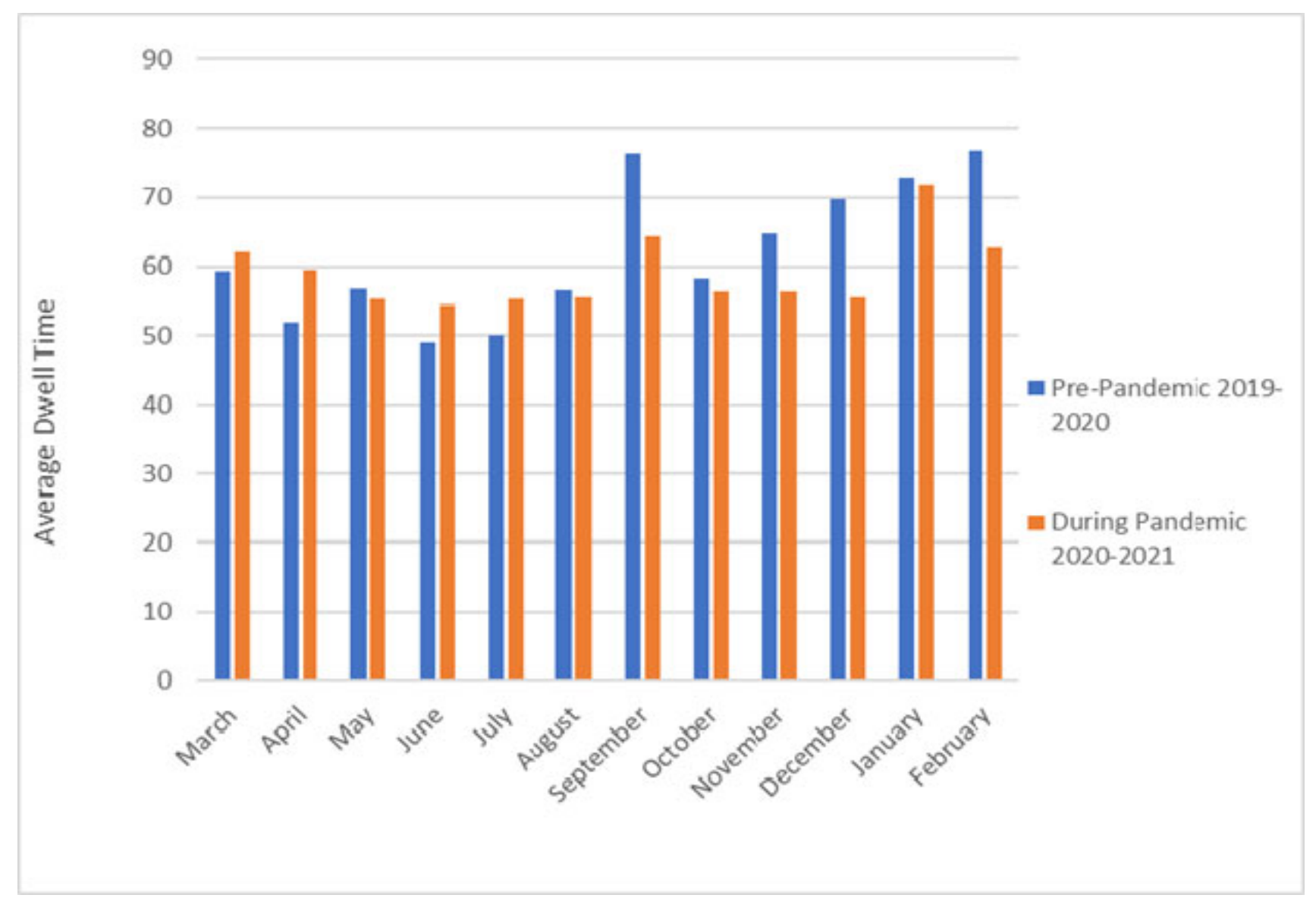

Figure 5. Average visitor dwell times for food and beverage retailers 
In order to measure the differences in consumer visitation for independent and chained retailers pre and during the pandemic a pared t-test was conducted. The difference in visitor data for chain stores $(\overline{\mathrm{x}}=8121.1 ; \sigma 2$ $=249333.7)$ and independent stores $(\overline{\mathrm{x}}=6331.92 ; \sigma 2=$ 616157.2) was significant $(\mathrm{t}=15.45641$; $\mathrm{DF}=49$; $\mathrm{Sig}=$ $0.01)$. Independent stores experienced greater declines in visitors during the pandemic than that of retail chains.

While visitation data highlighted substantial changes during the pandemic, dwell times were relatively unchanged during the same period (Figure 4). There proved to be no statistical difference in the average consumer dwell times pre and during the pandemic for food and beverage retailers $(\mathrm{t}=1.25 ; \mathrm{DF}=11 ; \mathrm{Sig}<0.1)$. Therefore, there was no statistical difference in the amount of time that consumers spent in food and beverage stores.

\section{Conclusion}

With the virus continuing to spread across the world, this paper provides a look at the changes in consumer visitation patterns within essential retail spaces. Demand for in-store shopping has declined along with the different phases of government intervention. Those retailers deemed as 'essential' services, along with non-essential retailers, collectively experienced a shift towards curbside pickup and online orders as many consumers felt less comfortable being in physical spaces. Most critically, this paper assessed how essential retail travel was affected by government policy. Changes in customer visitation was largely linked to the government lockdowns experienced in Erie County.

While all retail has experienced changes in demand and consumer interaction, there are some clear differences that exist between chain and independent retailers. Independent grocery retailers are more vulnerable as they experienced greater declines in visitor counts within this study period. If these independent retailers lack online channels to continue to engage with their consumers, this loss in business can result in major financial burdens.

While there is a large body of literature examining business failures, specifically the why and how companies fail $[42,43]$, the findings of this study contribute to research into the impact of COVID-19 on the retail industry. This paper provides a snapshot into the nature and extent of fluctuations in customer visitation patterns between chain and independent stores through cycles of restrictive government policy.

\subsection{Limitations}

This study has several limitations. The first limitation exists around the geometry associated with the geofences. Delineating geofences is a manual and often subjective process therefore leading to potential errors around the inclusion and exclusion of certain data points. The geofences for this data, in GIS form, were not made available and therefore could not be validated for accuracy. This made it difficult to validate the level of precision with polygon delineation. Another limitation is associated with the incompleteness and inconsistency in the data. The visitor counts were very low at the individual store level, therefore data had to be aggregated to broader categories (chain vs independent, as opposed to specific retailers). Lastly, assumptions are made around the data points as it is assumed that all recorded individuals are consumers in the stores, which is difficult to validate. While POI data with predefined geofences is more widely available for academic research, detailed point data at the individual-level is needed to be able to refine research methodologies to address detailed spatialtemporal questions.

\section{References}

1. World Health Organization (WHO) (2020, March 11). WHO Director-General's opening remarks at the media briefing on COVID-19 - 11 March 2020. WHO. https:/www.who.int/director-general/speeches/detail/whodirector-general-s-opening-

2. Plume, J. (2020, February 12). The effects of Coronavirus on the international shipping. Easyship. https://www.easyship.com/blog/how-coronavirus-affectsshipping

3. Leone, L. A., Fleischhacker, S., Anderson-Steeves, B., Harper, K., Winkler, M., Racine, E., ... \& Gittelsohn, J. (2020). Healthy food retail during the COVID-19 pandemic: Challenges and future directions. International journal of environmental research and public health, 17(20), 7397.

4. Loske, D. (2020). The impact of COVID-19 on transport volume and freight capacity dynamics: An empirical analysis in German food retail logistics. Transportation Research Interdisciplinary Perspectives, 6, 100165.

5. Sum, Z. Z., \& Ow, C. J. (2021). Community pharmacy response to infection control during COVID-19. A crosssectional survey. Research in Social and Administrative Pharmacy, 17(1), 1845-1852.

6. Hall, M. C., Prayag, G., Fieger, P., \& Dyason, D. (2020). Beyond panic buying: consumption displacement and COVID19. Journal of Service Management.

7. Mahajan, K., \& Tomar, S. (2020). Here Today, Gone Tomorrow: COVID-19 and Supply Chain

Disruptions. Forthcoming, American Journal of Agricultural Economics.

8. Sharma, M., Luthra, S., Joshi, S., \& Kumar, A. (2021).

Accelerating retail supply chain performance against pandemic 
disruption: adopting resilient strategies to mitigate the long-term effects. Journal of Enterprise Information Management.

9. Berg, C. J., Callanan, R., Johnson, T. O., Schliecher, N. C., Sussman, S., Wagener, T. L., ... \& Henriksen, L. (2020). Vape shop and consumer activity during COVID-19 non-essential business closures in the USA. Tobacco control.

10. Bartik, A. W., Bertrand, M., Lin, F., Rothstein, J., \& Unrath, M. (2020). Measuring the labor market at the onset of the COVID-19 crisis (No. w27613). National Bureau of Economic Research.

11. Courtemanche, C. J., Garuccio, J., Le, A., Pinkston, J. C., \& Yelowitz, A. (2020). Did Social-Distancing Measures in Kentucky Help to Flatten the COVID-19 Curve?.

12. Chernozhukov, V., Kasahara, H., \& Schrimpf, P. (2021). Causal impact of masks, policies, behavior on early covid-19 pandemic in the US. Journal of Econometrics, 220(1), 23-62.

13. "What You Need to Know." New York Forward, 2020, forward.ny.gov/.

14. Flesch, B., Vatrapu, R., Mukkamala, R. R., \& Madsen, R. (2018). Visualization of Crowd Trajectory,

Geospatial Sets, and Audience Prediction at Roskilde Festival 2018. In ICIS 2018 Pre-Conference

Workshop Proceedings: Special Interest Group on Geographic Information Systems Association for Information Systems. AIS Electronic Library (AISeL).

15. Zimmerman, C., Madsen, R., Eliassen, H. H., \& Vatrapu, R. (2016). Space vs. Place: Comparing Spacebased Movements and Place-based Experiences at the Roskilde Festival 2015. Proceedings of the 7th 2016 International Conference on Social Media \& Society, London, United Kingdom.

16. Korsholm Poulsen, L., Dekkers, D., Wagenaar, N., Snijders, W., Lewinsky, B., Mukkamala, R. R., \&

Vatrapu, R. (2016). Green Cabs vs. Uber in New York City. In C. Pu, G. Fox, \& E. Damiani (Eds.), Proceedings of the 2016 IEEE International Congress on Big Data. BigData Congress 2016 (pp. 222-229). [7584941] IEEE.

https://doi.org/10.1109/BigDataCongress.2016.35

17. Aversa, J., Doherty, S., \& Hernandez, T. (2018). Big data analytics: The new boundaries of retail location decision making. Papers in Applied Geography, 4(4), 390-408.

18. Aversa, J., Hernandez, T., \& Doherty, S. (2020). Spatial Big Data and Business Location Decision-Making: Opportunities and Challenges. Regional Intelligence, 205-224.

19. Brooker, A. M. S., Aversa, J., \& Shaker, R. R. (2020). Identifying tourist experiences in Maui, Hawaii using mobile location data. Papers in Applied Geography, 6(2), 132-150.

20. Alaei, A. R., S. Becken, and B. Stantic. 2019. Sentiment analysis in tourism: Capitalizing on big data. Journal of Travel Research 58 (2):175-91.
21. Centobelli, P., and V. Ndou. 2019. Managing customer knowledge through the use of big data analytics in tourism research. Current Issues in Tourism 22 (15):1862-22.

22. Qin, S., J. Man, X. Wang, C. Li, H. Dong, and X. Ge. 2019. Applying big data analytics to monitor tourist flow for the scenic area operation management. Discrete Dynamics in Nature and Society 2019: 1-11

23. Simon, G. E. 2019. Big data from health records in mental health care: Hardly clairvoyant but already useful. JAMA Psychiatry 76 (4):349-50.

24. Bradlow, E., M. Gangwar, P. Kopalle, and S. Voleti. 2017. The role of big data and predictive analytics in retailing. Journal of Retailing 93(1):79-95.

25. Vatsavai, R., and V. Chandola. 2016. Guest editorial: Big spatial data. Geoinformatica 20(4):797-799

26. Li, J., F. Tao, Y. Cheng, and L. Zhao. 2015. Big Data in product lifecycle management. International Journal of Advanced Manufacturing Technology 81:667-684.

27. Dalton, C. M., L. Taylor, and J. Thatcher. 2016. Critical data studies: A dialog on data and space. Big Data \&Society 3(1).

28. Wang, Y., Xu, R., Schwartz, M., Ghosh, D., \& Chen, X. (2020). COVID-19 and retail grocery management: insights from a broad-based consumer survey. IEEE Engineering Management Review, 48(3), 202-211.

29. Dorcic, J., J. Komsic, and S. Markovic. 2019. Mobile technologies and applications towards smart tourism-State of the art. Tourism Review 74 (1):82-103.

30. Gursoy, D., C. Jurowski, and M. Uysal. 2002. Resident attitudes. Annals of Tourism Research 29 (1):79-105.

31. Phithakkitnukoon, S., T. Horanont, A. Witayangkurn, R. Siri, Y. Sekimoto, and R. Shibasaki. 2015.

Understanding tourist behavior using large-scale mobile sensing approach: A case study of mobile phone users in Japan. Pervasive and Mobile Computing 18:1839.

32. Hasnat, M. M., and S. Hasan. 2018. Identifying tourists and analyzing spatial patterns of their destinations from location-based social media data. Transportation Research Part C: Emerging Technologies 96:38-54.

33. Kirilenko, A. P., S. O. Stepchenkova, and J. M. Hernandez. 2019. Comparative clustering of destination attractions for different origin markets with network and spatial analses of online reviews. Tourism Management 72: 400-10.

34. Hardy, A., J. Aryal, and M. P. Wells. 2019. Comparing techniques for tracking: The case of Tourism Tracer in Tasmania. Australia. E-Review of Tourism Research 16 $(2 / 3): 84-94$. 
35. The Capgemini Research Institute (2020, April). The

Consumer and COVID-19: Global consumer sentiment research in the consumer products and retail industry. Capgemini.

https://www.capgemini.com/wp-

content/uploads/2020/04/Covid-19-Consumer-Behaviour-in-

CPR.pdf

36. Untaru, E. N., \& Han, H. (2021). Protective measures against COVID-19 and the business strategies of the retail enterprises: Differences in gender, age, education, and income among shoppers. Journal of Retailing and Consumer Services, 60, 102446.

37. Sohani, A., \& Fahmy, T. (2020). The impact of a pandemic on brand preference in purchasing decisions of food and hygiene products: a COVID-19 perspective [Master's Thesis, Kristianstad University]. https://www.divaportal.org/smash/get/diva2:1444267/FULLTEXT01.pdf

38. Brandtner, P., Darbanian, F., Falatouri, T., \& Udokwu, C. (2021). Impact of COVID-19 on the customer end of retail supply chains: A big data analysis of consumer satisfaction. Sustainability, 13(3), 1464.

39. U.S. Census Bureau (2019). American Community Survey. Retrieved

from https://data.census.gov/cedsci/table?q=Erie\%20County\&tid=AC SST1Y2019.S0101.

40. Hao, N., Wang, H. H., \& Zhou, Q. (2020). The impact of online grocery shopping on stockpile behavior in Covid-19. China Agricultural Economic Review.

41. Grashuis, J., Skevas, T., \& Segovia, M. S. (2020). Grocery shopping preferences during the COVID-19 pandemic. Sustainability, 12(13), 5369.

42. Martinez, M. G., Zouaghi, F., Marco, T. G., \& Robinson, C. (2019). What drives business failure? Exploring the role of internal and external knowledge capabilities during the global financial crisis. Journal of Business Research, 98, 441-449.

43. Yang, T., \& del Carmen Triana, M. (2019). Set up to fail: Explaining when women-led businesses are more likely to fail. Journal of Management, 45(3), 926-954. 